\title{
Impact of Blending on Strength Distribution of Ambient Cured Metakaolin and Palm Oil Fuel Ash Based Geopolymer Mortar
}

\author{
Taliat Ola Yusuf, Mohammad Ismail, Jamilu Usman, and Ainul H. Noruzman \\ Construction Research Centre, (UTM CRC), Faculty of Civil Engineering, Universiti Teknologi Malaysia, \\ 81310 Skudai, Johor Bahru, Malaysia \\ Correspondence should be addressed to Taliat Ola Yusuf; taliatyusuf@yahoo.com
}

Received 9 February 2014; Accepted 14 August 2014; Published 31 August 2014

Academic Editor: Manolis Papadrakakis

Copyright (C) 2014 Taliat Ola Yusuf et al. This is an open access article distributed under the Creative Commons Attribution License, which permits unrestricted use, distribution, and reproduction in any medium, provided the original work is properly cited.

This paper investigates the influence of blending of metakaolin with silica rich palm oil fuel ash (POFA) on the strength distribution of geopolymer mortar. The broadness of strength distribution of quasi-brittle to brittle materials depends strongly on the existence of flaws such as voids, microcracks, and impurities in the material. Blending of materials containing alumina and silica with the objective of improving the performance of geopolymer makes comprehensive characterization necessary. The Weibull distribution is used to study the strength distribution and the reliability of geopolymer mortar specimens prepared from 100\% metakaolin, $50 \%$ and $70 \%$ palm and cured under ambient condition. Mortar prisms and cubes were used to test the materials in flexure and compression, respectively, at 28 days and the results were analyzed using Weibull distribution. In flexure, Weibull modulus increased with POFA replacement, indicating reduced broadness of strength distribution from an increased homogeneity of the material. Modulus, however, decreased with increase in replacement of POFA in the specimens tested under compression. It is concluded that Weibull distribution is suitable for analyses of the blended geopolymer system. While porous microstructure is mainly responsible for flexural failure, heterogeneity of reaction relics is responsible for the compression failure.

\section{Introduction}

Concrete made from Portland cement is described as quasibrittle with features strongly influenced by mechanical and chemical behavior of micro- to mesostructures when subjected to stresses [1]. The fracture behavior is thus affected by the existence of microdefects in the form of microcracks, voids, and weak heterogeneous zones in the material [13]. Consideration of hardened concrete fracture behavior is therefore paramount in structural safety assessment [4]. The random nature of cracks or flaws brings about scatter in strength and therefore lends support for statistical consideration. Normal distribution has been commonly used to describe the strength behavior of concrete materials. The use of the normal distribution is appealing because of its simplicity. However, it is limited by parameter prescription of scale factor extending to negative values even though the strength at fracture of a material cannot take on values less than zero [5]. Furthermore, the chance of obtaining the crack size greater than critical crack increases with volume of test specimens and this volume dependency is responsible for a decrease in the mean strength as the volume of specimen increases bringing about invariant problem with respect to parameters of normal distribution $[6,7]$. The lack of theoretical basis for the application of normal distribution sets it against other distributions with deep theoretical considerations [8]. A rational basis is the characterization of material strength based on extreme value distributions because a material fails by the weakest link manifested by the largest flaw in the material. The distribution of sample tests, for instance, is skewed to follow the tail of population distribution necessitating focus on extreme values at tail to yield parametric functions applied in extreme value statistical models [9]. Gumbel, Frechet, and Weibull distributions are examples of extreme value distributions. However, the Weibull distribution is favored because of its bounds that limit the lowest fracture strength to zero and the flexibility of the shape parameter; a relatively small number of test specimens can provide reasonably accurate estimates of failures and it provides graphical plots very 
useful for result analysis [9]. Brittle materials like ceramics are commonly characterized using Weibull distribution function $[6,10]$ because the statistics of the mechanical and failure properties adequately fit into the Weibull distribution [11]. ASTM C1239 [12] provides detail procedures for implementation of Weibull distribution in structural designs using ceramics. Studies have also reported the use of Weibull distribution to successfully describe the strength data of ordinary Portland cement concrete $[8,13]$. It was reported that the Weibull distribution gave the best result for concrete mechanical properties when compared to normal and log normal distributions [14].

Geopolymer as cementitious material prepared from activation of aluminosilicate such as fly ash and metakaolin with alkaline solution from sodium/potassium hydroxide and silicate has evolved as alternative to Portland base cementitious material such as mortar and concrete. Oven cured fly ash based geopolymer concrete was found to behave in a more brittle manner than the conventional Portland cement based concrete [15]. It has also been reported that fly ash based geopolymer concrete and paste have less characteristic fracture length than those of the ordinary Portland cement concrete, accompanied by a decrease in fracture energy and modulus of elasticity and increase in tensile splitting strength of the geopolymer concrete indicating a higher brittleness of the geopolymer [16]. It was further reported that matrix of formation of fly ash geopolymer and OPC concrete through geopolymerization and hydration reactions, respectively, is responsible for the difference in their behavior [16]. This should be expected because geopolymer, an X-ray amorphous inorganic polymeric material, falls within the broad group of ceramic materials [17] which are good examples of brittle materials. Geopolymer is a group of cementitious materials formed by activating aluminosilicate based material with alkaline solution containing a mixture of hydroxide and silicate of alkali earth metal (sodium or potassium). The reaction between trivalent aluminum and tetravalent silicon forms long ranged covalent and ionic bond of polymeric networks.

Brittleness in ceramics results in wide strength distributions that limit its use in construction. The brittle nature of geopolymer is therefore a motivation for characterization of its strength and distribution. This is specifically needed to understand the behavior of the material which may be influenced by the heterogeneity arising from the use of waste materials as the primary source of aluminosilicate requirements for its synthesis. For instance, the use of metakaolin for geopolymer production is limited by high demand for activating alkali due to relatively low silica/alumina ratio [18]. Also morphology of the particles necessitates excessive water demand to achieve adequate flow; else high shear mixing would have to be used $[19,20]$. This may be detrimental to the performance of the geopolymer especially with respect to shrinkage [19] and behavior under exposure to fire [21]. To solve this problem, metakaolin may be blended with silica rich waste materials such as palm oil fuel ash (POFA) that would reduce costs, adjust the silica alumina ratio to reduce alkali demand, and at the same time preserve mechanical and durability properties. The effect of blending on strength statistics is therefore important for a complete characterization of the material. This however is rarely reported in the literature.

This paper therefore studied the effect of varying POFA composition on strength distribution of metakaolin based geopolymer cured in ambient condition by application of the Weibull distribution. The characteristic strength can also be determined to give a measure of reliability of the material strength. The significance of this is that geopolymer as an emerging material may further be characterized in terms of strength and reliability and give insight into the implication of blending, especially with waste materials.

\section{Experimental Program}

2.1. Materials. Metakaolin obtained from calcined kaolin at $750^{\circ} \mathrm{C}$ for 4 hours in the furnace was blended with POFA sourced from a palm oil factory in southern Malaysia. POFA was treated by sieving to collect particles passing through 150 -micron sieve. This was followed by grinding in Los Angeles abrasion machine for 5 hours to obtain 95\% of particle size less than 45 microns. The chemical composition of metakaolin and POFA as determined by X-ray fluorescence (XRF) is contained in Table 1. A mixture of sodium silicate and sodium hydroxide was used for the preparation of geopolymer mortar specimens.

2.2. Methods. Geopolymer mortar prisms $(40 \times 40 \times 160 \mathrm{~mm})$ and cubes $(50 \times 50 \times 50 \mathrm{~mm})$ were prepared from metakaolin and POFA as precursor materials to determine the flexural and compressive strength of 20 specimens for each data set at three levels of blends of $100 \%, 50 \%$, and $30 \%$ by weight of metakaolin with $0 \%, 50 \%$, and $70 \%$ weight of POFA, respectively. The twenty specimens for each series were prepared by activating alumina and silica from metakaolin and POFA with alkaline solution made from sodium hydroxide $(\mathrm{NaOH})$ and sodium silicate $\left(\mathrm{Na}_{2} \mathrm{SiO}_{3}\right)$. The mix proportion is presented in Table 2. The specimens were removed from the moulds 24 hours after casting and were kept at ambient temperature of about $27^{\circ} \mathrm{C}$ for 28 days. The prism specimens were tested in 3-point load configuration to obtain the flexural strength using Inspiron testing machine with a loading rate of $1 \mathrm{KN} / \mathrm{s}$. The compressive strength was obtained from a universal testing machine also at a loading rate of $1 \mathrm{KN} / \mathrm{s}$. Field emission scanning electron microscopy (FESEM) was used to obtain information about the microstructure of the tested samples.

\subsection{Application of Weibull Distribution for Strength Char-} acterization. Weibull distribution like other extreme value distributions is used to characterize occurrences that are dominantly influenced by the weakest link theory. The important assumption is that the failure of a material is measured by the weaker element possessing small strength. This theory forms the basis for reliability of the strength consideration 
TABLE 1: Chemical composition of Metakaolin and POFA.

\begin{tabular}{lccccccccccccc}
\hline Material & $\mathrm{SiO}_{2}$ & $\mathrm{Al}_{2} \mathrm{O}_{3}$ & $\mathrm{~K}_{2} \mathrm{O}$ & $\mathrm{Fe}_{2} \mathrm{O}_{3}$ & $\mathrm{CaO}$ & $\mathrm{P}_{2} \mathrm{O}_{5}$ & $\mathrm{MgO}$ & $\mathrm{SO}_{3}$ & $\mathrm{Cl}$ & $\mathrm{TiO}$ & $\mathrm{CO}_{2}$ \\
\hline Metakaolin & 54.7 & 39.9 & 2.58 & 1.43 & - & - & 0.7 & - & - & - & 0.1 \\
POFA & 63.70 & 3.68 & 9.15 & 6.27 & 5.97 & 4.26 & 4.11 & 1.59 & 1.59 & 0.30 & 0.1 \\
\hline
\end{tabular}

Table 2: Mix Design of Geopolymer Mortar.

\begin{tabular}{lccccccc}
\hline $\begin{array}{l}\text { Mix } \\
\text { MK: POFA }\end{array}$ & $\begin{array}{c}\text { Agg. } \\
{\left[\mathrm{kg} / \mathrm{m}^{3}\right]}\end{array}$ & $\begin{array}{c}\mathrm{MK} \\
{\left[\mathrm{kg} / \mathrm{m}^{3}\right]}\end{array}$ & $\begin{array}{c}\text { POFA } \\
{\left[\mathrm{kg} / \mathrm{m}^{3}\right]}\end{array}$ & $\begin{array}{c}\mathrm{Na}_{2} \mathrm{SiO}_{3} \\
{\left[\mathrm{~kg} / \mathrm{m}^{3}\right]}\end{array}$ & $\begin{array}{c}\mathrm{NaOH} \\
{\left[\mathrm{kg} / \mathrm{m}^{3}\right]}\end{array}$ & $\begin{array}{c}\text { Add. water } \\
{\left[\mathrm{kg} / \mathrm{m}^{3}\right]}\end{array}$ & $\begin{array}{c}\text { Total water } \\
\text { content }\end{array}$ \\
\hline $100: 0$ & 1680.0 & 560.00 & - & 443.20 & 155.20 & 2.67 & 349.59 \\
$50: 50$ & 1680.0 & 280.00 & 280.00 & 308.30 & 108.00 & 53.00 & 294.24 \\
$30: 70$ & 1680.0 & 168.00 & 392.00 & 205.48 & 72.00 & 110.00 & 270.89 \\
\hline
\end{tabular}

of brittle materials [2]. Weibull three-parameter cumulative probability function is given as

$$
P_{f}=1-\exp \left[-\left(\frac{\sigma-\sigma_{u}}{\sigma_{\theta}}\right)^{m}\right]
$$

where $u$ is the minimum stress below which the material will not fail and $m$ is shaping parameter called Weibull modulus and is the scale parameter also known as characteristic or reference strength, the value of which depends on the stress pattern, size of specimens $[9,12]$, material type, and processing [2]. The significance of $m$ as a material property is that it characterizes the brittleness of the material [22]. The Weibull modulus also reveals the characteristics, severity, and distribution of flaws with a low $m$ value implying a broad spectrum of strength distribution resulting from the nonuniform distribution of flaws, a high $m$ value indicative of homogeneity in flaw distribution resulting in a reduced strength distribution $[6,11]$, and the typical $m$ values for structural ceramics as influenced by processing route lying between 3 and 12 [6].

The stress parameter $u$ when set at zero in line with the fact that strength of materials cannot be below this limit yields the two-parameter distribution. However the three-parameter distribution may still be used for strength with a predetermined lower bound from results of proof or screening tests. With $u$ equal to zero, (1) becomes [9]

$$
P_{f}=1-\exp \left(-\left(\frac{\sigma}{\sigma_{\theta}}\right)^{m}\right)
$$

A double natural logarithm of (2) yields

$$
\begin{aligned}
\ln \left(1-P_{f}\right) & =-\left(\frac{\sigma}{\sigma_{\theta}}\right)^{m} \\
\ln \left[\ln \left(\frac{1}{1-P_{f}}\right)\right] & =m \ln \sigma-m \ln \sigma_{\theta} .
\end{aligned}
$$

The probability of fracture $P_{f}$ of sample is estimated from

$$
P_{f}=\frac{i-0.5}{N}
$$

where $N$ is the number of test specimens and $i$ is the datum [12]. Expression in (3) depicts the reliability of the material. In this study, the flexural strength of 20 specimens was ranked in ascending order and the corresponding $P_{f}$ was calculated using (4) to obtain the left side of(3)

Plotting the left side of (3) against $\ln$ on the right of strength data and fitting the data points yielded a line with a slope $m$ which is an estimate of the Weibull distribution. Similarly, the characteristic strength was determined by obtaining the value of strength that corresponds to a zero value of $\ln \left[\ln \left(1 / 1-P_{f}\right)\right]$ or $P_{f}$ of $63.2 \%$. The curve fitting was performed using linear regression analysis [23].

\section{Results and Discussion}

3.1. Effect of POFA Blend on the Stress-Strain Behavior. The flexural stress-strain curves of three specimens at 28 days each from the 20 specimens of $100 \%$ metakaolin, 50\% POFA, and $70 \%$ POFA are illustrated in Figure 1. All the three samples show abrupt failure at varying peak stresses with the strains at failure being $0.003,0.0028$, and 0.0024 , respectively, and the absence of the plastic range indicating the brittleness of the material. Apart from stress decrease with increase in POFA, blending with POFA does show the influence on brittleness given the reduction in the steepness of the stressstrain curves with increasing POFA. Brittleness is attributed to the existence of high geopolymerization products [24].

3.2. Regression Analysis of Geopolymer Weibull Plots. The linear fitting of experimental data in Figures 2 and 3 indicates adequate regression coefficient $\left(R^{2}\right)$ of the plots. The model terms for the different mixes are indicated on the graphs. To further confirm the closeness of the test data with the regression data, analysis of variance (ANOVA) was performed. Only the ANOVA of mix with $100 \%$ metakaolin is presented in Table 3. The ANOVA tests confirmed that, at 0.05 levels, the regression data is not significantly different from the test data for all the mixes. Similar results were obtained in all the mixes confirming the adequacy of the Weibull regression models.

Tables 4 and 5 illustrate the comparison between Weibull and normal distribution parameters. The Weibull characteristic strengths for the mixes are more conservative when compared to those evaluated for normal distribution, for instance, at the usual 0.05 significant levels. From the study of Tumidajski et al. [8] it is not obvious that the Weibull modulus 
TABLE 3: One Way ANOVA of 100\% metakaolin geopolymer Weibull regression.

\begin{tabular}{lcccc}
\hline & DF & Sum of Squares & Mean Square & $F$ Value \\
\hline Model & 1 & $1.64034 E-6$ & $1.64034 E-6$ & $1.073222 E-6$ \\
Error & 38 & 58.08007 & 1.52842 & \\
Total & $\mathbf{3 9}$ & $\mathbf{5 8 . 0 8 0 0 7}$ & & \\
\hline & & Homogeneity of Variance Test & \\
Model & 1 & 0.00931 & 0.00931 & 0.01583 \\
Error & $\mathbf{3 8}$ & $\mathbf{2 2 . 3 5 0 3 5}$ & $\mathbf{0 . 5 8 8 1 7}$ & 0.90054 \\
\hline
\end{tabular}

TABle 4: Comparison of Weibull and Normal Distribution Parameters for Flexural Strength.

\begin{tabular}{|c|c|c|c|c|}
\hline \multirow[b]{2}{*}{ Mix } & \multicolumn{2}{|c|}{ Weibull } & \multicolumn{2}{|c|}{ Normal } \\
\hline & $\begin{array}{l}\text { Characteristic } \\
\text { Strength (MPa) }\end{array}$ & Modulus & $\begin{array}{l}\text { Mean Strength } \\
(\mathrm{MPa})\end{array}$ & $\begin{array}{l}\text { Standard } \\
\text { Deviation }\end{array}$ \\
\hline $100 \% \mathrm{MK}$ & 14.35 & 9.76 & 13.64 & 1.69 \\
\hline $50 \%$ POFA & 11.97 & 11.55 & 11.45 & 1.18 \\
\hline $70 \%$ POFA & 9.47 & 16.59 & 9.08 & 0.65 \\
\hline
\end{tabular}

TABle 5: Comparison of Weibull and Normal Distribution Parameters for Flexural Strength.

\begin{tabular}{lcccc}
\hline \multirow{2}{*}{ Mix } & $\begin{array}{c}\text { Weibull } \\
\text { Characteristic } \\
\text { Strength (MPa) }\end{array}$ & Modulus & $\begin{array}{c}\text { Mean Strength } \\
(\mathrm{MPa})\end{array}$ & $\begin{array}{c}\text { Standard } \\
\text { Deviation }\end{array}$ \\
\hline $100 \%$ MK & 67.40 & 15.56 & 67.12 & 5.22 \\
$50 \%$ POFA & 60.58 & 14.74 & 58.41 & 5.03 \\
$70 \%$ POFA & 48.95 & 12.37 & 43.83 & 4.04 \\
\hline
\end{tabular}

directly depended on the characteristic strength and as such it cannot be concluded here also that obvious relationship exists.

3.3. Effect of Blending on Strength Distribution. Using Weibull plots of Figure 3 to study the effect of blend on the distribution of the strength, it was observed that, generally, the Weibull modulus for flexural strength increased with replacement of metakaolin by POFA, indicating that flexural strength variability reduces with increase in POFA content. It can be observed in Figure 2 that the slope of the line for the $100 \%$ metakaolin geopolymer is 9.763 which is an estimate of Weibull modulus for the set of pure metakaolin specimens. A slope of 11.3 was obtained from specimens with 50\% POFA replacement while that for $70 \%$ POFA replacement is 16.69 which are in tandem with the brittle behavior of Figure 1. This tends to indicate that the ceramic-like behavior (wide strength distribution) of the geopolymer samples reduces with increase in POFA replacement considering that modulus for ceramics lies between 3 and 12 [6].

The microstructure of specimens prepared from 100\% metakaolin revealed heterogeneous grain comprising loose structured precipitates forming around the sheetlike packing of unreacted metakaolin with interconnected pores (Figure 4(b)). This may be responsible for the broad characteristic strength of the specimen as the sheetlike arrangement

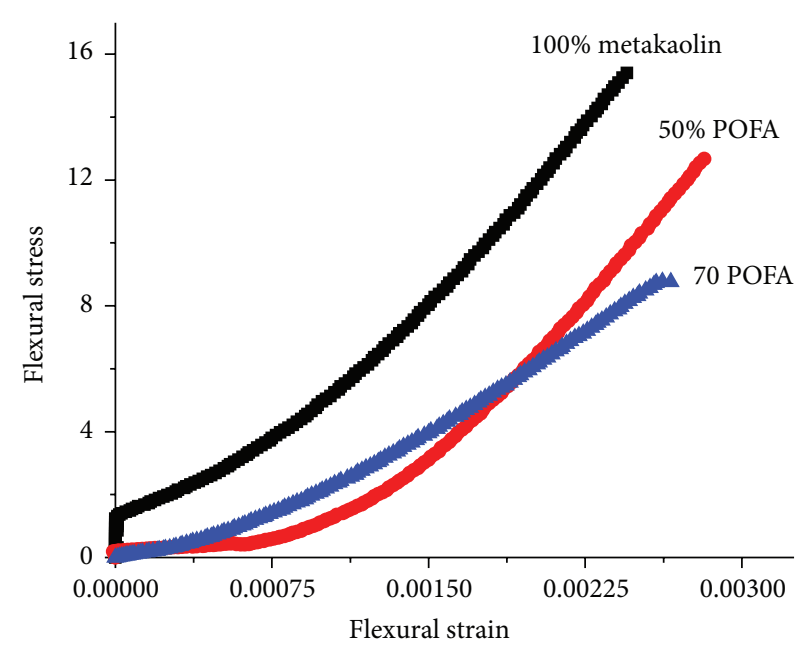

FIGURE 1: Influence of POFA on stress-strain behavior geopolymer specimen.

with micropores gives way to more homogenous densely packed microstructure with reduced micropores as the POFA replacements in the specimens increased to $50 \%$ and $70 \%$. The $\mathrm{Si} / \mathrm{Al}$ ratio of $100 \%$ metakaolin which is less than 3 $(\mathrm{Si} / \mathrm{Al}=2.41)$ leads to the formation of geopolymer with stiff and brittle properties as its three-dimensional structure of cross-linked rigid networks [25] fails abruptly in the presence of flaws such as voids (Figure $4(\mathrm{~b})$ ). The higher Si/Al ratios of $50 \%$ and $70 \%$ POFA blended geopolymers $(\mathrm{Si} / \mathrm{Al}=$ 4.49 and 6.72 ) tend to form a less rigid structure transiting from a three-dimensional to a two-dimensional network. The wriggles observed in the curves of $50 \%$ and $70 \%$ POFA (Figure 2) may be attributed to flaws from volume distributed relics of POFA in the microstructure [9]. The pure metakaolin specimen has the lowest Weibull modulus falling in the range of ceramic material (3 to 12 ). That for $50 \%$ POFA replacement barely falls in the range while that for $70 \%$ replacement is outside the range of ceramic. The implication of this is that the pure metakaolin system with the lowest Weibull modulus has broad flexural strength distribution and that for $70 \%$ has narrow flexural strength distribution with $50 \%$ falling in-between. As earlier mentioned, narrow distribution is a feature of a relatively homogeneous distribution of flaws. Material presenting narrow strength distribution is preferable because such a material is more predictable and has the least chance of failure at a stress lower than the characteristic value [9]. 


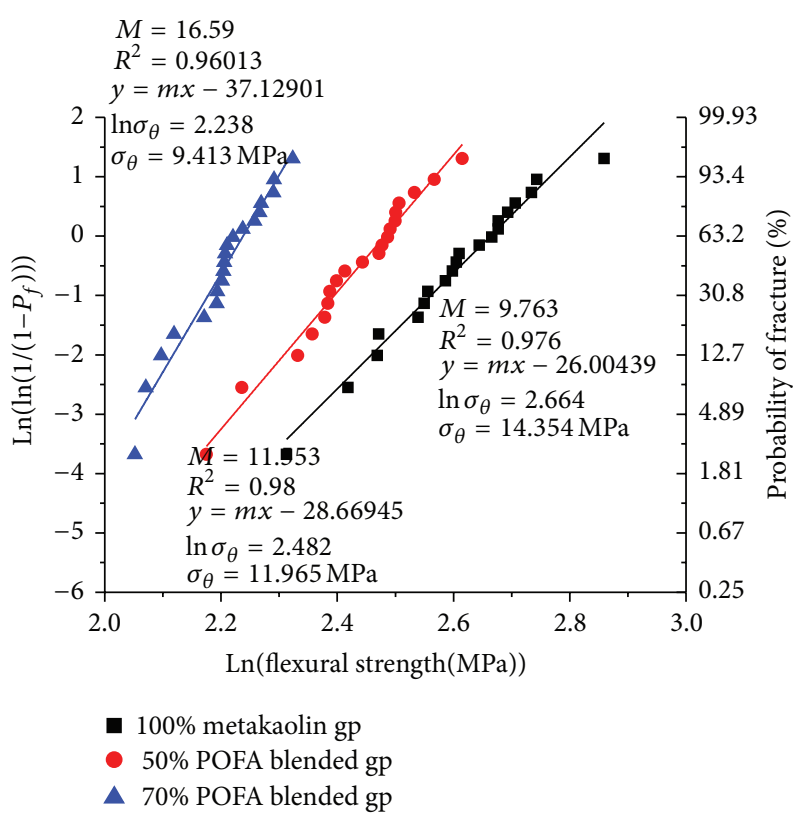

FIGURE 2: Weibull graph of flexural strength of blended geopolymer.

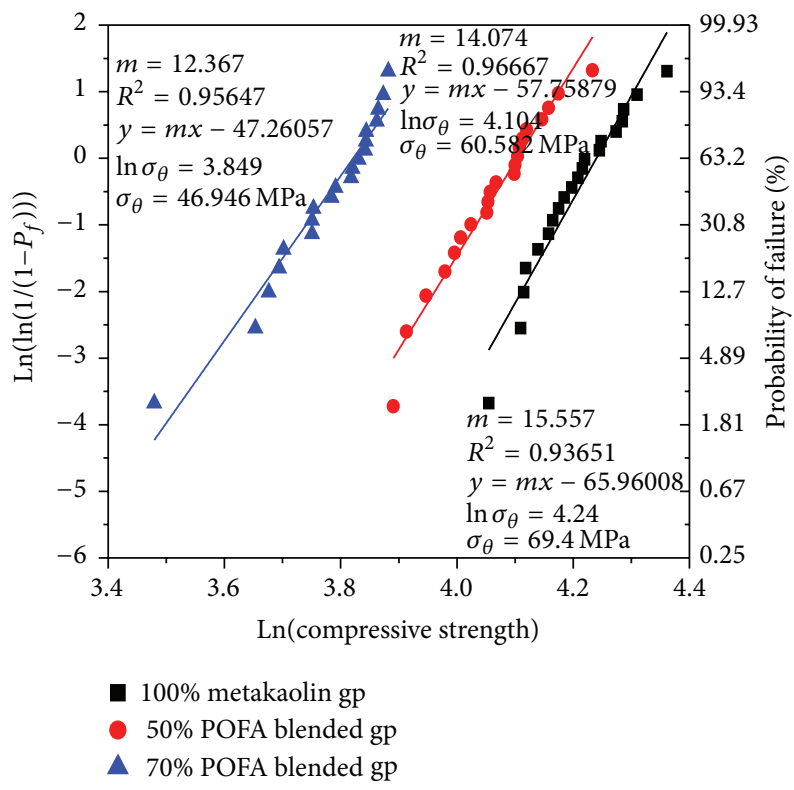

FIGURE 3: Weibull graph of compressive strength of blended geopolymer.

The Weibull modulus for compression strength of $100 \%$ metakaolin and 50\% and 70\% POFA replacement is shown in Figure 3. The modulus for geopolymer with $100 \%$ metakaolin and $50 \%$ and $70 \%$ POFA is $15.557,14.070$, and 12.367 , respectively. This shows that variability is the highest for geopolymer with $70 \%$ POFA and the lowest for that with $100 \%$ metakaolin under compression loading.

It is interesting to note that while the strength variability increased with POFA replacement in compression test, the opposite is the case for bending strength. Also, Weibull variability trends in compression also differ from that of a normal distribution of Table 4. This may be due to the fact that Weibull variability results mainly from flaws in the material structure. Furthermore, fracture in bending is mainly influenced by micropores which are seen to be predominant in the pure metakaolin system (Figure 4(b)) while variability in compressive failure may be due to heterogeneity caused by unreacted POFA which are noticeable in Figures 4(c) and 4(d). The failure mode in compression may be as a result of slow propagation of many cracks that coalesced to create a crushing zone as against the rapid and unstable crack development typical of flexural failure [8]. While the presence of reaction relics may be playing a major role in the crushing failure of specimens, the micropores may be the dominant factor responsible for scatter in flexural failure.

3.4. Effect of Blending on Characteristic Strength. The Weibull characteristic flexural strength obtained at $63.2 \%$ probability of fracture is the highest with a value of $14.339 \mathrm{MPa}$ for the geopolymer samples prepared with $100 \%$ metakaolin (Figure 2). Characteristic strength values reduced with increasing POFA replacement to give values of $12.013 \mathrm{MPa}$ and $9.38 \mathrm{MPa}$ for $50 \%$ and $70 \%$ POFA replacement, respectively. The characteristic flexural strength gives an indication of the fracture toughness of the material as an increase in strength depicts increase in fracture toughness [26]. The higher characteristic strength for pure metakaolin based geopolymer may therefore result in high fracture toughness even though it manifested relatively broad band distribution of brittle materials.

In a similar manner, characteristic compressive strength decreased with POFA replacement as indicated in Figure 3. The characteristic compressive strengths are $69.4 \mathrm{MPa}$, $60.58 \mathrm{MPa}$, and 46.95 $\mathrm{MPa}$ for $100 \%$ metakaolin and $50 \%$ and $70 \%$ POFA, respectively.

The trend of both characteristic flexural and compressive strengths due to POFA replacement may be as a result of $\mathrm{Si} / \mathrm{Al}$ ratio of the primary material which plays a major role in the strength of geopolymer. The availability of silica and alumina influences the extent and rate of polymeric reaction. Hypothetically, the strength of the geopolymer should increase with increase in the $\mathrm{Si} / \mathrm{Al}$ ratio because $\mathrm{Si}-$ $\mathrm{O}-\mathrm{Si}$ bonds, which are stronger than $\mathrm{Si}-\mathrm{O}-\mathrm{Al}$ and $\mathrm{Al}-\mathrm{O}-$ $\mathrm{Al}$ bonds, should be more with increase in $\mathrm{Si} / \mathrm{Al}$ ratio. This is however usually not the case due to some other synthesis factors [27]. Increase in POFA replacement raises the $\mathrm{Si} / \mathrm{Al}$ ratio from 2.41 for pure metakaolin geopolymer to 4.49 and 6.72 for $50 \%$ and $70 \%$ POFA mixes, respectively. The high volume replacement with POFA may prevent complete reaction of the materials leaving behind relics as observed in Figures $4(\mathrm{c})$ and $4(\mathrm{~d})$. The reduction in strength may therefore be due to the existence of these relics that have not been used in the polymerization process. They form the volume distributed flaws that act as the "weakest link" in the microstructure, thus becoming the major determinant of the fracture strength of the material.

3.5. Field Emission Scanning Electron Microscopy. Field emission scanning electron microscopy (FESEM) micrographs 


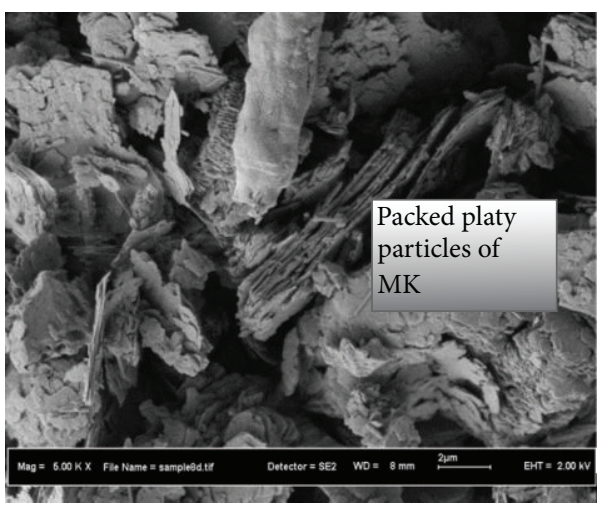

(a) Metakaolin powder

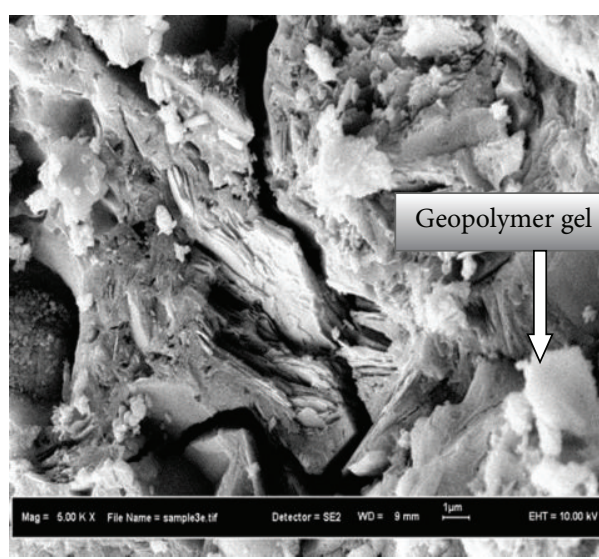

(c) 50\% POFA geopolymer

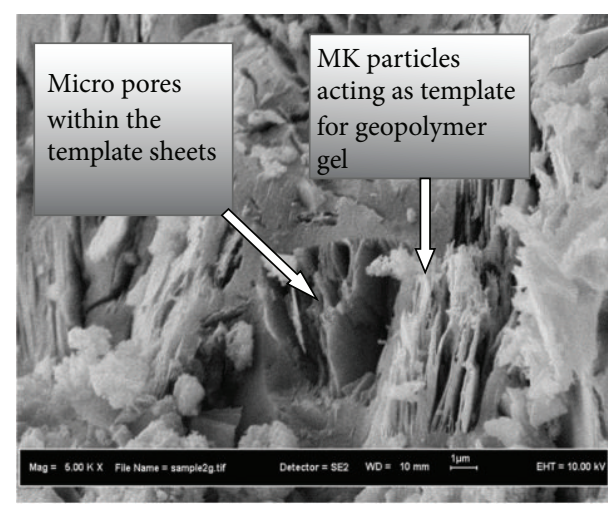

(b) $100 \%$ MK geopolymer

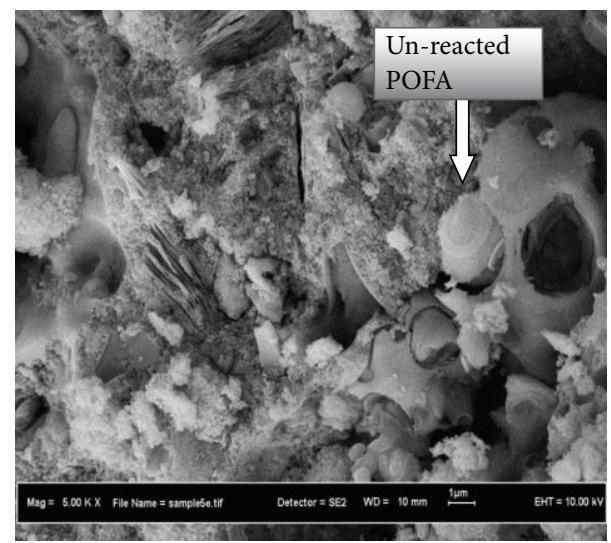

(d) $70 \%$ POFA geopolymer

FIGURE 4: FESEM of metakaolin powder and geopolymer specimens.

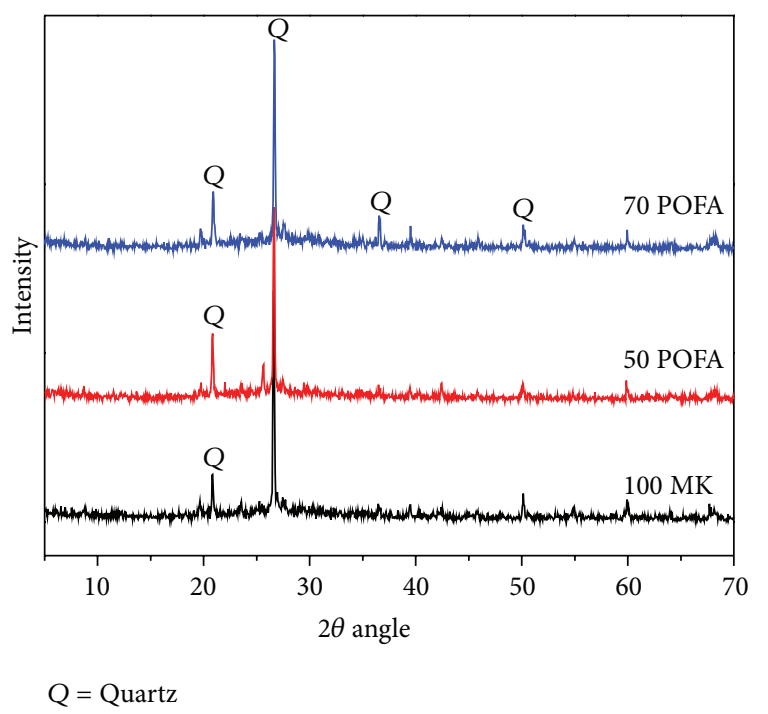

FIGURE 5: X-ray diffraction of 28-day ambient cured geopolymer.

of metakaolin starting material are shown in Figure 3 and those of geopolymer specimen are shown in Figures 4(a), $4(\mathrm{~b}), 4(\mathrm{c})$, and 4(d). The gel formation in the microstructure of the metakaolin geopolymer is shown in Figure 4(b) to be predominantly formed to take after the platy sheets of metakaolin. This arrangement does not allow for complete filling of spaces between the sheets by the gel. The micropores also observed by Hawa et al. [28] vary in volume and size within the entire microstructure. The marked difference in grain direction of the sheets which are irregularly arranged could result in varying the induced microresistance to applied load by different specimen depending on the nature of formed gel laminates and hence the broad distribution of strength at failure observed in flexural loading.

The micrograph of 50\% POFA specimen in Figure 4(c) presents less packed gel laminates that take after the metakaolin particle shapes in the microstructure. The reduced presence of the sheetlike grains suggests a better consistency in the gel formation that may be responsible for the reduced flexural strength variability. However, there exist some artifacts from incomplete reaction of metakaolin rubbing off on the homogeneity of the microstructure. The relics which appeared to be minimally distributed tend to have influence on the variability of compressive strength in a similar manner. Figure $4(\mathrm{~d})$ showing the micrograph of $70 \%$ POFA mortar revealed a microstructure with a noticeable presence of POFA relics and absence of the platy grain gel. 
3.6. X-Ray Diffraction. The XRD patterns of the geopolymer mortar are shown in Figure 5. The broad band and low intensity patterns exhibited between $24^{\circ}$ and $28^{\circ}$ at 2-theta angle for three specimens indicate a high degree of amorphous structure of the mortar which is characteristic of geopolymer [29]. The crystalline peaks observed are associated with starting materials. There are no significant differences in phases observed with the increase in POFA replacements at 28 days, suggesting that the variability observed may not be as a result of the mineralogical content of the geopolymer.

\section{Conclusion}

Based on the results obtained in this study, the following conclusions can be made.

(1) Weibull distribution can be used to characterize the flexural and compressive strength distribution of geopolymer blended with high volume metakaolin and POFA. It can also be used to prescribe the threshold value of a reliable strength of the blended geopolymer depicted by the Weibull characteristic strength.

(2) The Weibull distribution used to characterize the flexural strength distribution of metakaolin blended geopolymer showed that the pure metakaolin geopolymer specimen has the least homogeneity with broad flexural strength distribution as depicted by the Weibull modulus meaning that blend with POFA improves the strength distribution of the POFA blended geopolymer through the filling of the porous microstructure by reaction products of metakaolin and POFA. On the other hand, the compressive strength distribution of the specimens increased with POFA is attributed to the influence of heterogeneous reaction relics of the system.

(3) The characteristic flexural and compressive strengths of the specimens generally reduced with POFA blend with the $70 \%$ POFA blend having the least strength mainly as a result of increase in $\mathrm{Si} / \mathrm{Al}$ ratio leading to existence of reaction relics.

\section{Conflict of Interests}

The authors declare that there is no conflict of interests regarding the publication of this paper.

\section{Acknowledgment}

The authors gratefully acknowledge the financial support of RMC, GUP, Grant no. 03H35, Universiti Teknologi Malaysia.

\section{References}

[1] S. M. Vrech and G. Etse, "Gradient and fracture energybased plasticity theory for quasi-brittle materials like concrete," Computer Methods in Applied Mechanics and Engineering, vol. 199, no. 1-4, pp. 136-147, 2009.

[2] J. H. Andreasen, "Reliability-based design of ceramics," Materials \& Design, vol. 15, no. 1, pp. 3-13, 1994.
[3] A. Carpinteri, J. Xu, G. Lacidogna, and A. Manuello, "Reliable onset time determination and source location of acoustic emissions in concrete structures," Cement and Concrete Composites, vol. 34, no. 4, pp. 529-537, 2012.

[4] M. H. A. Beygi, M. T. Kazemi, I. M. Nikbin, and J. V. Amiri, "The effect of water to cement ratio on fracture parameters and brittleness of self-compacting concrete," Materials \& Design, vol. 50, pp. 267-276, 2013.

[5] M. Elgueta, G. Díaz, S. Zamorano, and P. Kittl, "On the use of the Weibull and the normal cumulative probability models in structural design," Materials and Design, vol. 28, no. 9, pp. 24962499, 2007.

[6] B. Basu, D. Tiwari, D. Kundu, and R. Prasad, "Is Weibull distribution the most appropriate statistical strength distribution for brittle materials?" Ceramics International, vol. 35, no. 1, pp. 237-246, 2009.

[7] R. Danzer, P. Supancic, J. Pascual, and T. Lube, "Fracture statistics of ceramics-weibull statistics and deviations from Weibull statistics," Engineering Fracture Mechanics, vol. 74, no. 18, pp. 2919-2932, 2007.

[8] P. J. Tumidajski, L. Fiore, T. Khodabocus, M. Lachemi, and R. Pari, "Comparison of Weibull and normal distributions for concrete compressive strengths," Canadian Journal of Civil Engineering, vol. 33, no. 10, pp. 1287-1292, 2006.

[9] J. B. Quinn and G. D. Quinn, "A practical and systematic review of Weibull statistics for reporting strengths of dental materials," Dental Materials, vol. 26, no. 2, pp. 135-147, 2010.

[10] B. Stawarczyk, M. Özcan, A. Trottmann, C. H. F. Hämmerle, and M. Roos, "Evaluation of flexural strength of hipped and presintered zirconia using different estimation methods of Weibull statistics," Journal of the Mechanical Behavior of Biomedical Materials, vol. 10, pp. 227-234, 2012.

[11] T.-F. Wong, R. H. C. Wong, K. T. Chau, and C. A. Tang, "Microcrack statistics, Weibull distribution and micromechanical modeling of compressive failure in rock," Mechanics of Materials, vol. 38, no. 7, pp. 664-681, 2006.

[12] ASTMC1239-07, Standard Practice for Reporting Uniaxial Strength Data and Estimating Weibull Distrbution Parameters for Advanced Ceramics, ASTM International, West Conshohocken, Pa, USA, 2007.

[13] M. Diamaruya, H. Kobayashi, and T. Nonaka, "Impact tensile strength and fracture of concrete," Journal de Physique IV France, vol. 7, pp. C3-253-C3-258, 1997.

[14] X. Chen, S. Wu, and J. Zhou, "Analysis of mechanical properties of concrete cores using statistical approach," Magazine of Concrete Research, vol. 65, no. 24, pp. 1463-1471, 2013.

[15] P. K. Sarker, R. Haque, and K. V. Ramgolam, "Fracture behaviour of heat cured fly ash based geopolymer concrete," Materials and Design, vol. 44, pp. 580-586, 2013.

[16] Z. Pan, J. G. Sanjayan, and B. V. Rangan, "Fracture properties of geopolymer paste and concrete," Magazine of Concrete Research, vol. 63, no. 10, pp. 763-771, 2011.

[17] Y. J. Zhang, S. Li, Y. C. Wang, and D. L. Xu, "Microstructural and strength evolutions of geopolymer composite reinforced by resin exposed to elevated temperature," Journal of NonCrystalline Solids, vol. 358, no. 3, pp. 620-624, 2012.

[18] G. Habert, J. B. D'Espinose De Lacaillerie, and N. Roussel, "An environmental evaluation of geopolymer based concrete production: Reviewing current research trends," Journal of Cleaner Production, vol. 19, no. 11, pp. 1229-1238, 2011. 
[19] C. Kuenzel, L. J. Vandeperre, S. Donatello, A. R. Boccaccini, and C. Cheeseman, "Ambient temperature drying shrinkage and cracking in metakaolin-based geopolymers," Journal of the American Ceramic Society, vol. 95, no. 10, pp. 3270-3277, 2012.

[20] J. L. Bell and W. M. Kriven, "Preparation of ceramic foams from metakaolin-based geopolymer gels," in Developments in Strategic Materials: Ceramic Engineering and Science Proceedings, Volume 29, Issue 10, pp. 96-111, John Wiley \& Sons, 2009.

[21] D. L. Y. Kong, J. G. Sanjayan, and K. Sagoe-Crentsil, "Comparative performance of geopolymers made with metakaolin and fly ash after exposure to elevated temperatures," Cement and Concrete Research, vol. 37, no. 12, pp. 1583-1589, 2007.

[22] K. Trustrum and A. D. S. Jayatilaka, "On estimating the Weibull modulus for a brittle material," Journal of Materials Science, vol. 14, no. 5, pp. 1080-1084, 1979.

[23] X. X. He and Z. H. Xie, "Experimental study on statistical parameters of concrete strength based on weibull probability distribution," Key Engineering Materials, vol. 477, pp. 224-232, 2011.

[24] J. He, "Sytheses and characterization of geopolymers for infrastructural applications," in Civil and Environmental Engineering, p. 115, Louisiana State University and Agricultural and Mechanical College, 2012.

[25] J. He, J. Zhang, Y. Yu, and G. Zhang, "The strength and microstructure of two geopolymers derived from metakaolin and red mud-fly ash admixture: a comparative study," Construction and Building Materials, vol. 30, pp. 80-91, 2012.

[26] R. Gettu, Z. P. Bazant, and M. E. Karr, "Fracture properties and brittleness of high-strength concrete," ACI Materials Journal, vol. 87, no. 6, pp. 608-618, 1990.

[27] P. Duxson, J. L. Provis, G. C. Lukey, S. W. Mallicoat, W. M. Kriven, and J. S. J. van Deventer, "Understanding the relationship between geopolymer composition, microstructure and mechanical properties," Colloids and Surfaces A: Physicochemical and Engineering Aspects, vol. 269, no. 1-3, pp. 47-58, 2005.

[28] A. Hawa, D. Tonnayopas, and W. Prachasaree, "Performance evaluation and microstructure characterization of metakaolinbased geopolymer containing oil palm ash," The ScientificWorld Journal, vol. 2013, Article ID 857586, 9 pages, 2013.

[29] R. R. Lloyd, "Accelerated ageing of geopolymers," in Geopolymers, Structure, Processing, Properties and Industrial Applications, J. L. Provis and J. S. J. van Derventer, Eds., pp. 139-166, Woodhead Publishing, 2009. 

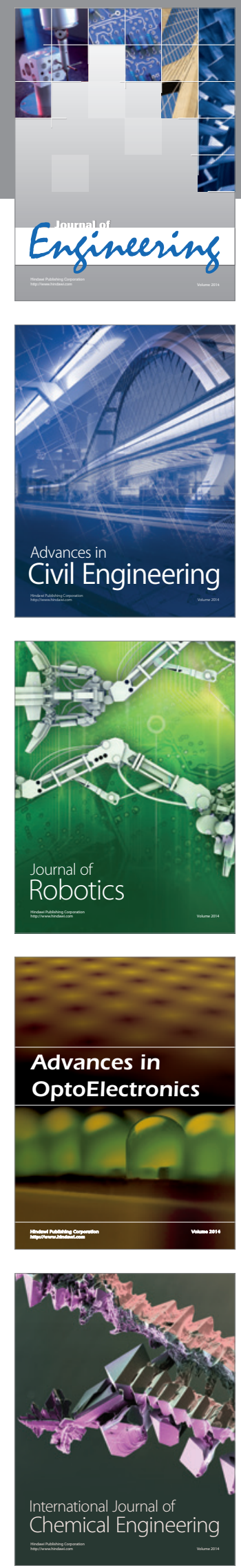

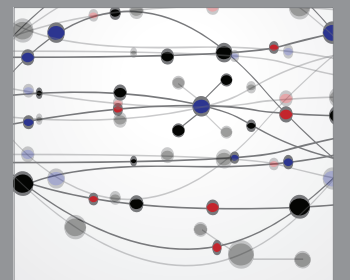

The Scientific World Journal
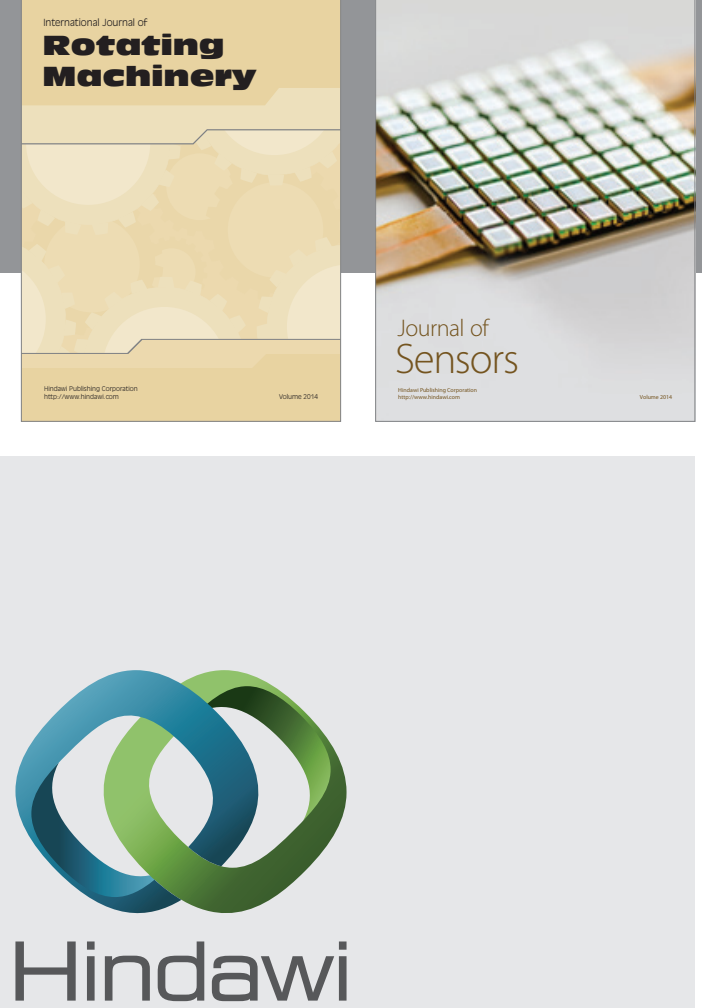

Submit your manuscripts at http://www.hindawi.com
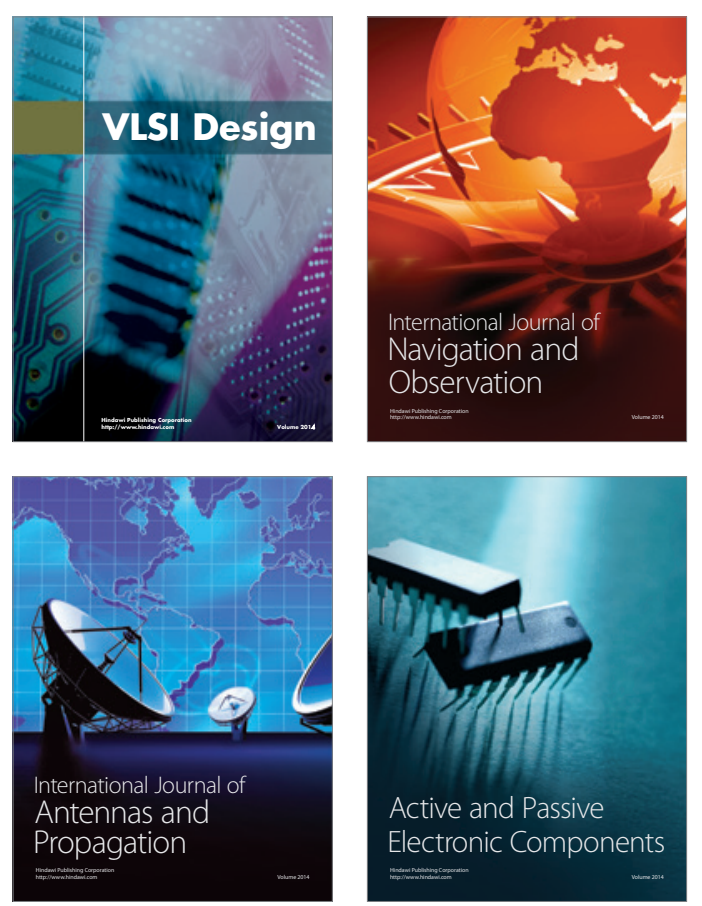
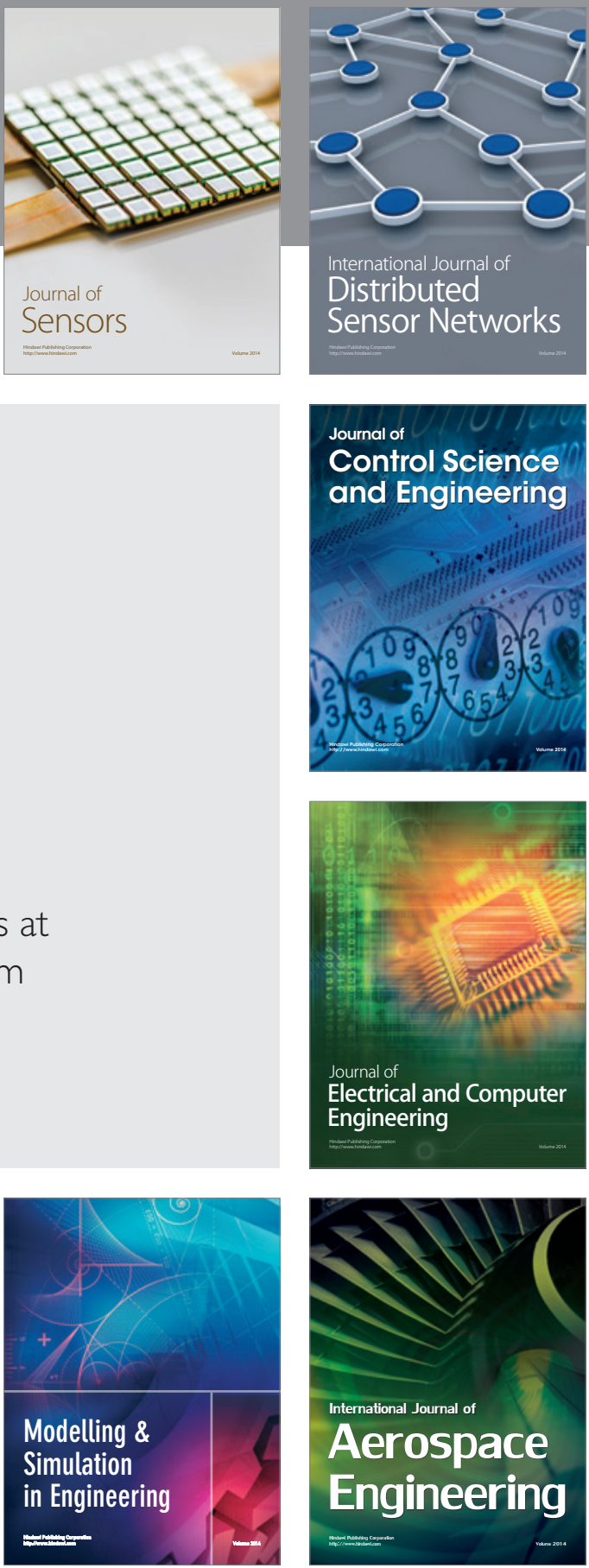

Journal of

Control Science

and Engineering
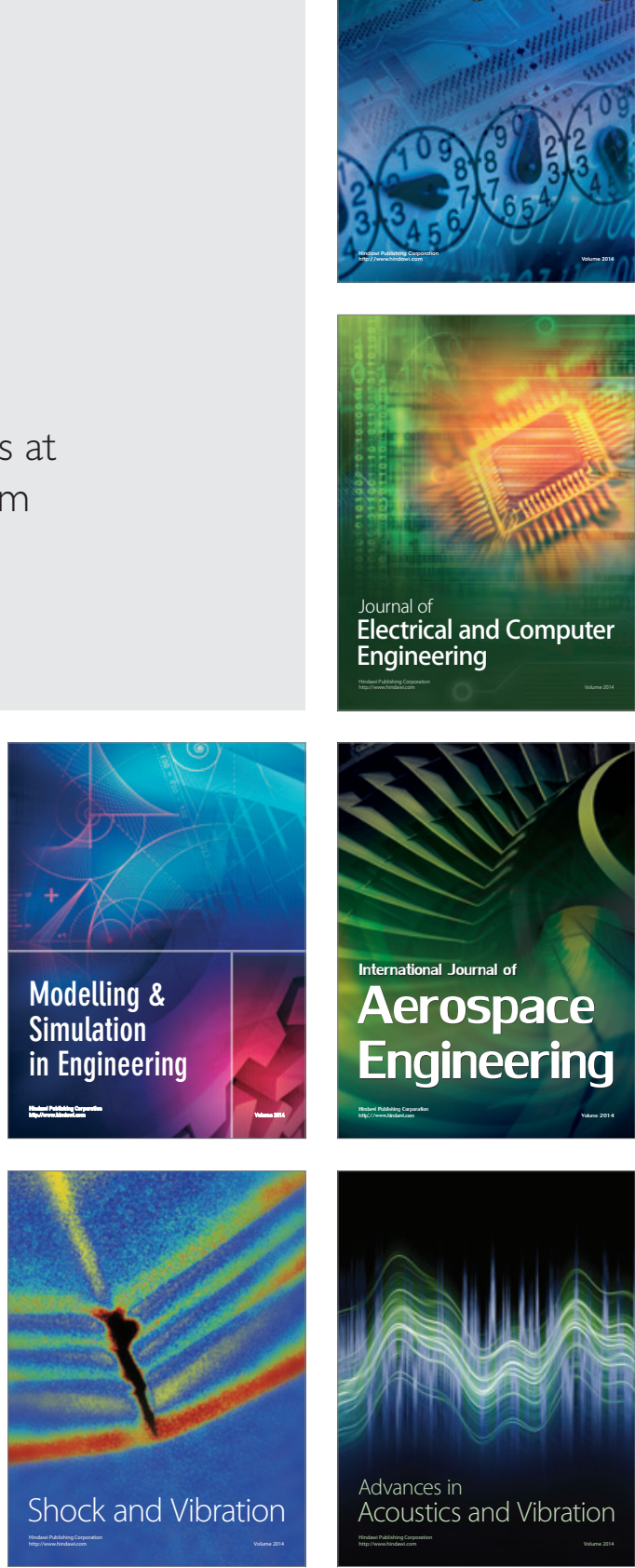